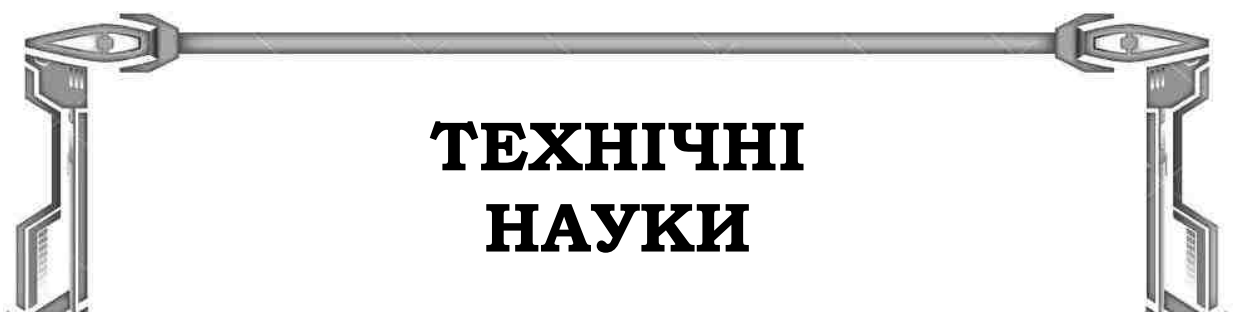

УДК 631.313.6

\author{
Василинич М. А. ${ }^{1}$ \\ аспірант \\ E-mail: vasylynych.n.a@gmail.com \\ Дуганець B. I. ${ }^{1}$ \\ д-р. пед. наук професор, зав. кафедри професійної освіти \\ E-mail:duganec.viktor@gmail.com \\ Панцир Ю. I. ${ }^{1}$ \\ канд. техн. наук, доиент \\ декан інженерно-технічного факультету \\ E-mail: panziryuriy@gmail.com \\ ${ }^{1}$ Подільський державний аграрно-технічний університет \\ Кам'янеиь-Подільський, Украӥна

\section{ПРОЦЕС РІЗАННЯ ГРУНТУ НОЖАМИ РОТОРА КОМБІНОВАНОГО ЛЕМІШНО-ПОЛИЦЕВОГО ПЛУГА}

\begin{abstract}
Анотація
Обробіток трунту є найбільш енергоємним та затратним процесом, тому створення комбінованих мамин, виконуючих за один робочий прохід декілька операцій $\epsilon$ актуальним питанням на сьогодні, вирішення якого нерозривно пов'язане з об'єднанням сільськогосподарських операцій в один технологічний процес, щуо приносить економічні, організаційні та агробіологічні переваги.

Виходячи з особливостей підготовки трунту під посів чи посадку сільськогосподарських культур як об'єкту, та необхідності подальшого наукового проектування комбінованого технологічного процесу обробітку трунту внесення добрив, активного кришення пласта та заробки кореневих, рослинних решток та добрив як предмету, метою наукових досліджень є аналіз взаємодї ротора з пластом, визначення та оптимізація основних параметрів ножів, радіуса, частоти обертання з огляду на забезпечення класичного різання трунту і перемішування з добривами.

В Подільському державному агротехнічному університеті розроблено конструкиію комбінованого плуга, технологічний процес роботи якого об’ єднує операції глибокої оранки, активне подрібнення пласта і заробки кореневих і пожнивних решток, а також внесення мінеральних добрив.

$B$ результаті досліджень обтрунтовано кути установки ножа по відношенню радіуса ротора $\alpha$, кута загострення $\gamma$, кута різання чр, затилочного кута Ц, кута конусності ротора $\beta$, кута зміщення лопастей (променів) кріплення, величини трансформації кута загострення. Проведено аналіз сил, діючих на частинку трунту, і визначено необхідну частоту обертання, при якій трунт проходить по поверхні ножа без завантаження, при изьом забезпечується ефект його розвантаження.
\end{abstract}

Ключові слова: комбінований плуг; ротор; ножі; параметри; режсии роботи; добрива; кришення; рослинні залишки; різання; трансформація. 
Вступ. В сучасній системі обробітку грунту найбільш енергоємними, а, відповідно, затратними є операції обробітку грунту, зокрема глибокого рихлення орного шару з оборотом чи без обороту пласта.

Якщо врахувати, що в основному обробітку грунту передують операції внесення добрив, а після оранки проводять ряд технологічних прийомів поверхневого обробітку грунту, в цілому технологічний процес займає вагому долю в собівартості вирощування сільськогосподарських культур, призводить до збільшення термінів виконання робіт, $\epsilon$ причиною пересушування і ущільнення верхнього шару, що часто буває причиною погіршення умов розвитку рослин.

Наведена інформація є організаційно-біологічною підставою об'єднання окремо взятих операцій в один комплекс i, відповідно, створенню комбінованих машин.

Більшість грунтообробних машин, які використовуються в сільському господарстві працюють в тяговому режимі, отримуючи необхідну енергію через причіпні пристрої енергетичного засобу. Існуючі колісні або гусеничні ходові системи тракторів забезпечують коефіцієнт корисної дії (ККД) машинно-тракторного агрегату (МТА) в межах $0,5 \ldots 0,7$. [1].

Дія енергії на робочі органи грунтообробних машин через вал відбору потужності (ВВП) відповідає сучасним тенденціям розвитку тракторів, а використання активних грунтообробних елементів в машині зменшує тяговий опір на 20-30\% за рахунок виникнення реактивної сили на ножах $[2,3]$.

Наведена інформація є технологічною підставою об'єднання «пасивного» та «активного» обробітку грунту.

Традиційно добрива вносяться перед оранкою, рідше перед поверхневим обробітком грунту. При цьому використовують різного типу розкидачі.

Однак, якість поверхневого внесення добрива в силу різних причин (технологічних, кліматичних тощо) не завжди відповідає агровимогам. Тим більше, науковими дослідженнями, виробничим досвідом доведено, що більш раціональним і агробіологічно оптимальним $\epsilon$ локальне, пошарове внесення добрив, в розрізі обробленого грунту пропорційно майбутнього розвитку сільськогосподарської культури і розміщення іїі кореневої системи $[4,5,6]$.

Вищенаведене є біологічною підставою для об'єднання операції внесення добрива 3 основним обробітком грунту та розподіл їх локально по глибині орного шару.

Відповідно, створення технічних засобів, які би виконували за один робочий прохід основний обробіток грунту, локальне внесення добрив та активне кришення грунту, моделювання та науковий супровід процесів проектування, $є$ проблемою актуальною і на часі.

Аналіз останніх досліджень та публікацій. Питанням розробки технологічної схеми комбінованого плуга, конструкції роторів, обгрунтуванню технологічних параметрів і режимів роботи основних елементів плуга присвячено наукові дослідження I.М. Панова, В.І. Ветохина, В.А. Шмоніна (Росія).

Науковий пошук в основному базувався на теорії кришення пласта ротором на основі удару [1, 2, 3, 4, 5, 6].

Велику роботу з наукового супроводу створення комбінованих плугів проведено в Білорусії такими вченими, як 3.В. Ловкіс, І.М. Бендера, М.Д. Подскребко.

Дослідження білоруських вчених базувалися на робочій гіпотезі ефективності кришення пласта ротором через процес різання ножами.

Вивчалися питання вибору приводу роторів - механічний - М.Д. Подскребко [6], гідравлічний - 3.В. Ловкіс, I.М. Бендера [7, 8, 9, 10, 11].

Останніми дослідженнями слід вважати науковий пошук і оптимізацію роторів 
комбінованих плугів з криволінійними різальними елементами [12].

Питанням локального внесення мінеральних добрив присвячено дослідження В.А. Коваля, В.С. Муштая (Україна) $[13,14,15,16]$.

Останніми експериментальними дослідженнями доведено технологічну i агрономічну ефективність об'єднання операцій глибокого рихлення грунту глибокорозпушувачами та пошарового, локального внесення добрив на всю глибину рихлення.

Водночас, дослідження щодо внесення добрив під час обробітку грунту комбінованими плугами, обладнаними вертикальними роторами, практично відсутні, що визначає актуальність та мету дійсного дослідження.

Мета. Виходячи 3 особливостей підготовки грунту під посів чи посадку сільськогосподарських культур як об'єкту, необхідності подальшого наукового проектування комбінованого технологічного процесу обробітку грунту внесення добрив, активного кришення пласта та заробки кореневих, рослинних решток та добрив як предмету, метою наукових досліджень $є$ аналіз взаємодії ротора з пластом, визначення та оптимізація основних параметрів ножів, радіуса, частоти обертання 3 огляду на забезпечення класичного різання грунту і перемішування з добривами.

Відповідно до об'єкту, предмету і мети визначено наступні завдання досліджень:

- визначити просторове розміщення ножів по висоті ротора;

- визначити форми, кутів установки ножів до радіуса $\alpha$, різання $\psi_{\mathrm{p}}$, затилочного $\xi$, загострення $\gamma$, кута конусності ротора $\beta$ кута ковзання, $\varepsilon$ та коефіцієнта трансформації кута загострення.

- виконати аналіз сил діючих на частинку добрив і визначити величину частоти обертання ротора $\omega_{\text {p }}$ при якій приходить розвантаження ножів, як елемент процесу подрібнення пласта.

Методологія дослідження. Дослідження проводилися шляхом технологічно конструкційного аналізу технічних рішень існуючих комбінованих плугів, за результатами наукових досліджень вчених різних країн та математичного моделювання.

Результати. Кут установки ножа по відношенню до радіуса ротора $\alpha$, вибирається за умови забезпечення ковзання грунту по поверхні ножа (розвантаження ножа).

$$
\alpha \geq \frac{\pi}{2}-\psi_{\mathrm{p}}
$$

де $\alpha$ - кут тертя грунту по поверхні ножа.

Кут загострення різальної кромки $\gamma$. Теоретично, 3 огляду на енергозатрати процесу різання зменшення кута загострення призводить до зменшення опору різанню, однак процес затуплення має прискорений характер, що, в свою чергу, підвищує енергозатрати. Вважається оптимальним вибір значення $\gamma=20 \ldots 30^{\circ}[16]$.

Затилочний кут $\xi$ вибирається рівним $3 \ldots 5^{\circ}$. При цьому враховується ефект пружності відрізаної стружки і можливість виникнення тертя затилком ножа по пласту, що різко погіршує динаміку різання [16].

Кут різання визначається, як сума складових

$$
\psi_{\mathrm{p}}-\gamma+\xi ;
$$

Теоретичні та експериментальні дослідження процесів різання дають підстави вважати можливим зменшення кута різання $\psi_{\mathrm{p}}$ без зменшення кута загострення а через кінематичну трансформацію останнього. Кінетичну трансформацію кута загострення можна отримати через установку ножа під кутом до вертикалі 3 дотриманням кута установки $\beta$ по всій висоті (рис. 1).

де $a$ i $b$ - розміри пласта

$$
\beta=\arcsin \frac{a}{b}
$$




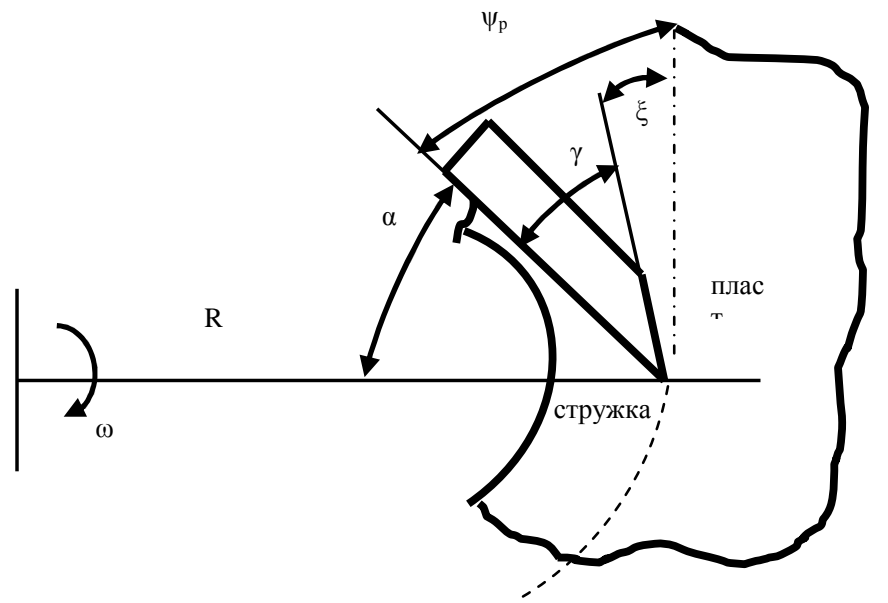

Рис. 1. Кути встановлення ножа

Реальний кут загострення $\gamma_{\mathrm{p}} 3$ врахуванням кута установки $\alpha$ буде рівним

$$
K_{\mathrm{p}}=\operatorname{arctg} \gamma \cdot \cos \beta
$$

При цьому величина коефіцієнта трансформації кута загострення визначається як

$$
R_{\mathrm{Tp}}=\frac{\gamma-\gamma_{\mathrm{p}}}{\gamma} ;
$$

Частота обертання ротора при, якій проходить розвантаження ножа визначаємо через аналіз сил, які діють на частинку грунту (стружку) при радіусі обертання $R$ і кута установки $\alpha$ (рис. 2).

На частинку стружки діють сили Каріоліса $\mathrm{F}_{\mathrm{\kappa}}$ та відцентрова $\mathrm{F}_{\mathrm{L}}$, Сила ваги (y вертикальній площині) $\mathrm{G}$.

Сила відцентрова, $\mathrm{F}_{\text {ц }}$

$$
G=m g ;
$$

Сила Каріоліса, $\mathrm{F}_{\mathrm{\kappa}}$

$$
F_{\text {ч }}=m \omega^{2} R
$$

$$
F_{\mathrm{rR}}=2 \bar{m} \omega^{2} R
$$

Враховуючи, що ножі розміщені до радіуса під кутом різання $\alpha$, на частинку стружки діють похідні сили по напрямах - дотичному і нормальному.

Сила дотична від сили Каріоліса, $\mathrm{T}_{\mathrm{\kappa}}$

$$
T_{\mathrm{rr}}=F_{\mathrm{K}} \cdot \sin \alpha=2 m \omega^{2} R \sin \alpha ;
$$

Сила дотична від сили центробіжної, $\mathrm{T}_{\text {ц }}$

$$
T_{\text {II }}=F_{\text {II }} \cdot \cos \alpha=m \omega^{2} R \cos \alpha \text {; }
$$

Сила нормальна від сили Каріоліса, $\mathrm{N}_{\kappa}$

$$
N_{\mathrm{K}}=F_{\mathrm{r}} \cdot \cos \alpha=2 m \omega^{2} R \cos \alpha ;
$$

Сила нормальна тиску від сили відцентрової, $\mathrm{N}_{\Perp}$

$$
N_{\text {ц }}=F_{\text {ц }} \cdot \sin \alpha=2 m \omega^{2} R \sin \alpha \text {; }
$$

Сила нормальна від сили ваги у вертикальній площині із врахуванням нахилу ножів у вертикалі ротора $\beta$.

$$
N_{G}=G \cdot \cos \beta=m g \cos \beta
$$



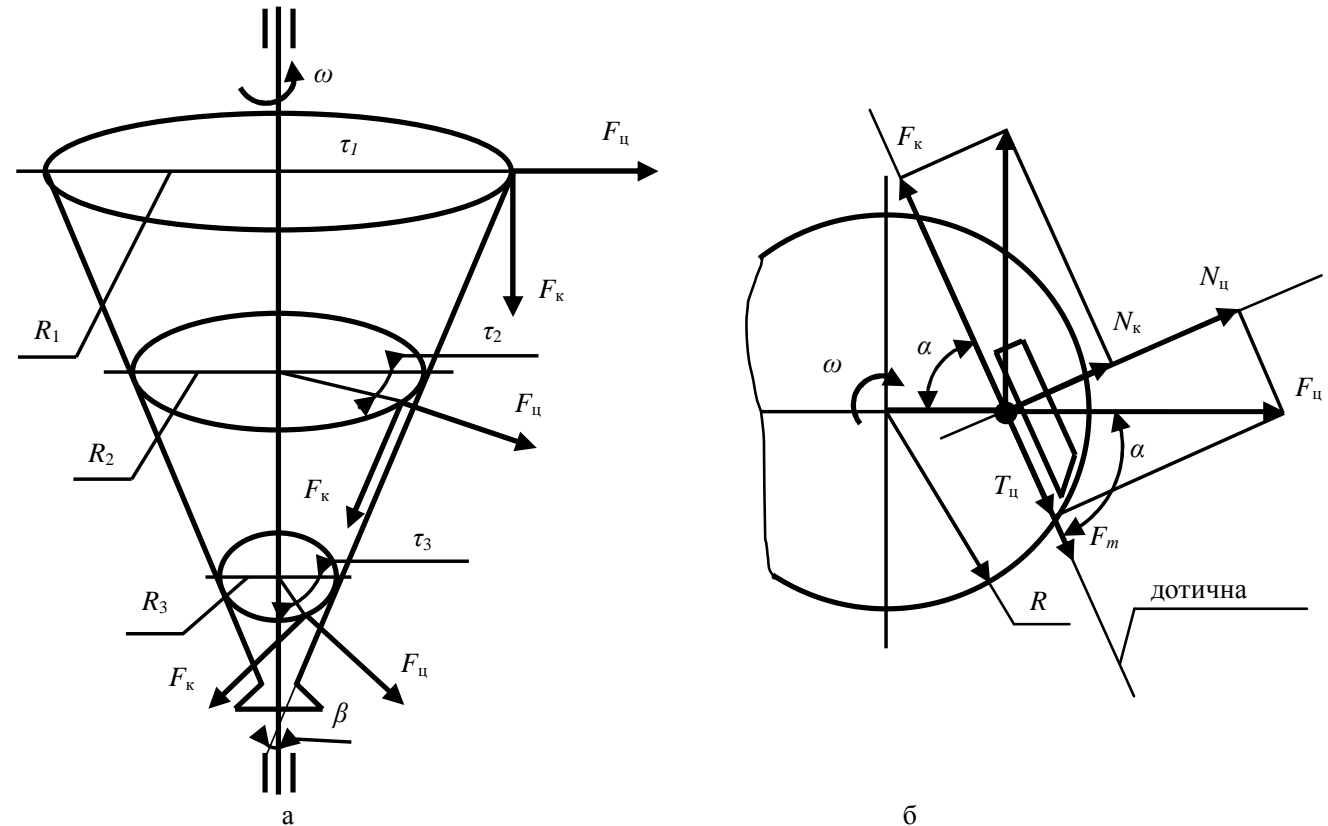

Puc. 2. Схема дії сил на частинки добрив

a - вертикальна площина; б - горизонтальна площина.

Сила тертя, $\mathrm{F}_{\mathrm{T}}$

$$
\begin{aligned}
& F_{m}=\sum N f ; \\
& F_{m}=\left(2 m \omega^{2} R \cos \alpha+m \omega^{2} R \sin \alpha+m g \cos \beta\right) \operatorname{tg} \varphi ;
\end{aligned}
$$

Умова розвантаження ножа (відносно руху стружки по внутрішній частині ножа)

$$
T_{\mathrm{rL}}>F_{m}+T_{\text {य }}
$$

$2 m \omega^{2} R \sin \alpha \geq 2 m \omega^{2} R \cos \alpha \operatorname{tg} \varphi+m \omega^{2} R \sin \alpha \operatorname{tg} \varphi+$ $m g \cos \beta \operatorname{tg} \varphi+m \omega^{2} R \cos \alpha$;

$\omega^{2}(2 m R \sin \alpha-2 m R \cos \alpha \operatorname{tg} \varphi-m R \sin \alpha \operatorname{tg} \varphi-m R \cos \alpha) \leq$ $m g \cos \beta \operatorname{tg} \varphi$;

$$
\omega \geq \sqrt{\frac{m g \cos \beta \operatorname{tg} \varphi}{2 m R \sin \alpha-2 m R \cos \alpha \operatorname{tg} \varphi-m R \sin \alpha \operatorname{tg} \varphi-m R \cos \alpha}} ;
$$

Рішенням рівняння отримуємо значення частоти обертання при якому проходить розвантаження ножів.

Висновки і перспективи. В результаті проведених теоретичних досліджень обгрунтовано кути установки ножа по відношенню радіуса ротора $\alpha$, кута загострення $\gamma$, кута різання $\psi_{\mathrm{p}}$, затилочного кута $\xi$, кута конусності ротора $\beta$, кута зміщення лопастей (променів) кріплення, величини трансформації кута загострення.

Проведено аналіз сил, діючих на частинку грунту (стружку) і визначено необхідну частоту обертання, при якій рух грунту проходить по поверхні ножа без завантаження, при цьому забезпечується ефект розвантаження ножа.

\section{Список використаних джерел}

1. Ветохин В.И., Панов И.М., Шмонин В.А., Юзбашев В.А. Тягово-приводные 
комбинированные почвообрабатывающие машины: Теория, расчет, результаты испытаний: монография. Киев : Феникс, 2009. 264 с.

2. Панов И.М., Шмонин В.А. Испытания прицепного пятикорпусного плуга с роторными отвалами. Тракторы и сельхозмашины. 1967. № 6. С. 21-23.

3. Панов И.М., Шмонин В.А. Плуги с комбинированными рабочими органами. Механизация и электрификаиия социалистического сельского хозяйства. 1968. № 11. С. 29-33.

4. Панов И.М., Шмонин В.А. Исследование работы комбинированного плужного корпуса. Тракторы и сельхозматины. 1969. № 8. С. 29-32.

5. Панов И.М., Шмонин В.А. Крошення почвы плугом с комбинированными плужными корпусами. Тракторы и сельхозмашиныл. 1970. № 2. С. 18-20.

6. Бендера И.Н., Андреев А.А. Определение оптимальной формы рабочего элемента ротора комбинированного плуга. Повышение производительности машинно-тракторных агрегатов. Доклады. Москва : МИИСП, 1985. С. 41-44.

7. Ловкис 3.В., Бендера И.Н. Обоснование формы ротора комбинированного плуга. Земледельческая механика. Доклады Москва : МИИСП, 1985. С. 17-19.

8. Ловкис 3.В., Бендера И.Н., Красноруцкий Н.В., Оскирко С.И. Стенд для изучения процесса резания почвы рабочими органами активных почвообрабатывающих машин. ППП БелНИИНТИ № 86-30. Минск, 1986. 5 с.

9. Ловкис 3.В., Бендера И.Н., Кустоянович С.Л. Полевые исследования работы комбинированного плуга с гидроприводом роторных отвалов, № 183 1986. Минск : БелНИИНТИ, 1986. 4 c.

10. Ловкис 3.В., Бендера И.Н. Плуг для обработки тяжелых переувлажненных почв с гидроприводом роторов. Тракторы и сельхозмашины. 1987. № 1. С. 12-14.

11. Катков П.И. Анализ конструкций комбинированных плугов. П.И. Катков, Б.А. Ахалая. Техника в сельском хозяйстве. № 6. 2006. С.32-34.

12. Лобачевский П.Я., Муштай В.С. Локальное внесение удобрений с рациональным распределением. Механизация растениеводства. 1990. № 5. С. 16-20.

13. Муштай В.С. Способ локального внесения минеральных удобрений комбинированным рабочим органом Збірник наукових праџь Луганського державного аграрного університету. 1999. № 4 (10). С. 76-80.

14. Муштай В.С. Некоторые теоретические исследования процесса распределения минеральных удобрений по глубине при локальном внесении. Збірник наукових праць Луганського державного аграрного університету. 1999. № 4 (10). С. 81-85.

15. Муштай В.С. Закономерности распределения минеральных удобрений по глубине при локальном внесении. Сборник научных работ Крымского государственного аграрного университета. 2005. № 84. С. 189-194.

16. Матюшин Ю.И., Гринчук И.М., Егоров Г.М. Расчет и проектирование ротационных почвообрабатывающих машин. Москва : Агропромиздат. 1988. 175 с.

Дата надходження статті до редакиії: 13.08.2019

Рецензування 24.09.2019 Прийняття в друк: 27.12.2019

Vasylynych N. A. ${ }^{1}$

PhD student

E-mail: vasylynych.n.a@gmail.com

Duganec V. I. ${ }^{1}$

Dr. Sc. (Pedag.), Professor

E-mail:duganec.viktor@gmail.com

Pantsyr Y. I. ${ }^{1}$

Ph.D. (Engineering), Associate Professor

E-mail: panziryuriy@gmail.com

${ }^{1}$ State Agrian and Engineering University in Podilya,

Kamianets-Podilskyi, Ukraine 


\title{
THE PROCESS OF SOIL CUTTING WITH ROTOR KNIVES OF COMBINED PLOUGHSHARING-RACKED PLOW
}

\begin{abstract}
Soil tillage is the most energy-intensive and costly process. Therefore, the creation of combined machines that perform multiple operations in one workflow is a pressing issue for today, the solution of which is inextricably linked to the integration of agricultural operations into one technological process that brings economic, organizational and agro-biological benefits.

Based on the peculiarities of soil preparation for planting or planting crops as an object, and the need for further scientific design of the combined technological process of soil application of fertilizers, active crumbling and cultivation of root, plant residues and fertilizers as a subject, the purpose of scientific research analysis of the interaction of the rotor with the reservoir, determination and optimization of the basic parameters of knives, radius, rotational speed with a view to providing classic soil cutting and mixing with fertilizers.

At State Agrarian and Engineering University in Podiya the design of the combined plow was developed. The technological process of their work combines the operations of deep plowing, the active grinding of the formation and the earning of root and crop residues, as well as the introduction of mineral fertilizers.

As a result of researches, the angles of installation of the knife with respect to the radius of the rotor $\alpha$, the angle of sharpening $\gamma$, the cutting angle $\psi$, the occipital angle $\zeta$, the angle of conicity of the rotor $\beta$, the angle of displacement of the blades (rays) of the attachment, the magnitude of the transformation of the angle of sharpening, the analysis of the part of the sharpening, and according to its results the required speed of rotation at which the soil passes on the surface of the knife without loading is determined and the effect of its unloading is provided.
\end{abstract}

Keywords: combined plow; rotor; knives; parameters; operating modes; fertilizers; roofing; plant residues; cutting; transformation.

\section{References}

1. Vetohin, V.I., Panov, I.M., Shmonin, V.A., \& Yuzbashev, V.A. (2009). Tyagovo-privodnyie kombinirovannyie pochvoobrabatyivayuschie mashinyi: Teoriya, raschet, rezultatyi ispyitaniy [Tractiondrive combined tillage machine.

Theory, calculation, test results]. Kyiv: Feniks. Retrieved from https://docplayer.ru/39118529-Vi-vetohin-i-m-panov-v-a-shmonin-v-a-yuzbashev-tyagovo-privodnye-kombinirovannye-

pochvoobrabatyvayushchie-mashiny.html [in Russian]

2. Panov, I.M., \& Shmonin, V.A. (1967). Ispyitaniya pritsepnogo pyatikorpusnogo pluga s rotornyimi otvalami [Tests of a trailed five-body plow with rotary dumps]. Traktoryi $i$ selhozmashinyi, 6 , 21-23. [in Russian]

3. Panov, I.M., \& Shmonin, V.A. (1968). Plugi s kombinirovannyimi rabochimi organami [Plows with combined working bodies]. Mehanizatsiya i elektrifikatsiya sotsialisticheskogo selskogo hozyaystva, 11, 29-33. [in Russian]

4. Panov, I.M., \& Shmonin, V.A. (1969). Issledovanie rabotyi kombinirovannogo pluzhnogo korpusa [The study of the combined plow body]. Traktoryi i selhozmashinyi. № 8. 29-32. [in Russian]

5. Panov, I.M., Shmonin, V.A. (1970). Kroshennya pochvyi plugom s kombinirovannyimi pluzhnyimi korpusami [Crushed soil with a plow with combined plow bodies]. Traktoryi i selhozmashinyi, 2, 18-20. [in Russian]

6. Bendera, I.N., Andreev, A.A. (1985). Opredelenie optimalnoy formyi rabochego elementa rotora kombinirovannogo pluga [Justification of the rotor shape of a combined plow]. Povyishenie proizvoditelnosti mashinno-traktornyih agregatov. Dokladyi. Moskow: MIISP, 41-44. [in Russian]

7. Lovkis, Z.V., Bendera, I.N. (1985). Obosnovanie formyi rotora kombinirovannogo pluga [Justification of the rotor shape of a combined plow]. Zemledelcheskaya mehanika. Doklady. Moskow: MIISP, 17-19. [in Russian]

8. Lovkis Z.V., Bendera I.N., Krasnorutskiy N.V., \& Oskirko S.I. (1986). Stend dlya izucheniya protsessa rezaniya pochvyi rabochimi organami aktivnyih pochvoobrabatyivayuschih mashin [A stand for studying the process of cutting soil by working bodies of active tillage machines]. PPP BelNIINTI № 8630. Minsk. [in Russian]

9. Lovkis, Z.V., Bendera, I.N., \& Kustoyanovich, S.L. (1986). Polevyie issledovaniya rabotyi kombinirovannogo pluga s gidroprivodom rotornyih otvalov [Field studies of the combined plow with 
hydraulic drive of rotary dumps] 183. Minsk: BelNIINTI, 4. [in Russian]

10. Lovkis Z.V., \& Bendera, I.N. (1987). Plug dlya obrabotki tyazhelyih pereuvlazhnennyih pochv $\mathrm{s}$ gidroprivodom rotorov [Plow for processing heavy waterlogged soils with hydraulic rotors]. Traktoryi $i$ selhozmashinyi, 1, 12-14. [in Russian]

11. Katkov, P.I., \& Ahalaya, B.A. (2006). Analiz konstruktsiy kombinirovannyih plugov [Analysis of the designs of combined plows].Tehnika $v$ selskom hozyaystve, 6, 32-34. [in Russian]

12. Lobachevskiy, P.Ya., \& Mushtay, V.S. (1990). Lokalnoe vnesenie udobreniy s ratsionalnyim raspredeleniem [Local fertilization with rational distribution]. Mehanizatsiya rastenievodstva, 5, 16-20. [in Russian]

13. Mushtay, V.S. (1999). Sposob lokalnogo vneseniya mineralnyih udobreniy kombinirovannyim rabochim organom [The method of local application of mineral fertilizers by the combined working body]. Zbirnik naukovih prats Luganskogo derzhavnogo agrarnogo unIversitetu, 4 (10), 76-80. [in Russian]

14. Mushtay, V.S. (1999). Nekotoryie teoreticheskie issledovaniya protsessa raspredeleniya mineralnyih udobreniy po glubine pri lokalnom vnesenii [Some theoretical studies of the distribution process of mineral fertilizers in depth at local application]. Zbirnik naukovih prats Luganskogo derzhavnogo agrarnogo unIversitetu, 4 (10), 81-85. [in Russian]

15. Mushtay, V.S. (2005). Zakonomernosti raspredeleniya mineralnyih udobreniy po glubine pri lokalnom vnesenii [Regularities of the distribution of mineral fertilizers in depth at local application]. Sbornik nauchnyih rabot Kryimskogo gosudarstvennogo agrarnogo universiteta, 84, 189-194. [in Russian]

16. Matyushin, Yu.I., Grinchuk, I.M., \& Egorov, G.M. (1988). Raschet i proektirovanie rotatsionnyih pochvoobrabatyivayuschih mashin [Calculation and design of rotary tillage machines]. Moskow: Agropromizdat. [in Russian] 